CLINICAL STUDY

\title{
Association of dehydroepiandrosterone-sulfate with endothelial function in young women with polycystic ovary syndrome
}

\author{
A Dagre, J Lekakis, C Mihas, A Protogerou, L Thalassinou, D Tryfonopoulos, G Douridas, C Papamichael \\ and M Alevizaki \\ Vascular Laboratory and Endocrine Unit, Department of Clinical Therapeutics, Alexandra University Hospital, Medical School, University of Athens, \\ Athens, Greece \\ (Correspondence should be addressed to A G Dagre 23 Ikarias Street, 14578 Ekali, Athens, Greece; Email: annadagre@hotmail.com)
}

\begin{abstract}
Objective: The aim of this study was to assess non-invasively endothelial function of young women with polycystic ovary syndrome (PCOS) in comparison with healthy age-matched women and a group of young women with idiopathic hirsutism $(\mathrm{IH})$. The possible role of metabolic and hormonal parameters on endothelial function was also examined.

Design: Descriptive clinical trial.

Methods: Fifty-six women, 27 with PCOS, 16 with IH and 13 healthy age-matched women were studied. Endothelial function of resistance arteries was assessed by venous occlusion plethysmography. Metabolic and hormonal parameters were estimated in this study population.

Results: The duration of reactive hyperemia (durRH) was shorter in PCOS group when compared with normal controls $(63.75 \pm 13.33 \mathrm{~s}$ vs $113.18 \pm 20.92 \mathrm{~s}, P=0.036)$. A similar finding was observed when PCOS were compared with IH group $(63.75 \pm 13.33 \mathrm{~s}$ vs $105 \pm 17.20 \mathrm{~s}, P=0.05)$. The durRH did not differ between IH and control group (105 $\pm 17.20 \mathrm{~s}$ vs $113.18 \pm 20.92 \mathrm{~s}$, ns). A significant positive linear correlation was found between the durRH and dehydroepiandrosterone-sulfate (DHEA-S) levels $(r=+0.48, P=0.04)$ in the PCOS group. The basal insulin resistance index (HOMA) differed significantly between PCOS, IH and control groups. There was no significant correlation between durRH and HOMA index or testosterone levels in the PCOS group.

Conclusions: Endothelial dysfunction may be an early sign of cardiovascular system abnormalities in young PCOS women. It is possible that increased DHEA-S levels may offer a cardioprotective advantage that attenuates the effects of cardiovascular risk factors that accompany PCOS.
\end{abstract}

European Journal of Endocrinology 154 883-890

\section{Introduction}

Metabolic and hormonal abnormalities involved in polycystic ovary syndrome (PCOS) such as insulin resistance, dyslipidemia, hypertension and hyperadrogenemia classify these women as a group with increased risk for future cardiovascular events (1-4). Women with PCOS thus constitute a metabolically intriguing group of young women suitable for investigating the combined effects of insulin resistance and sex steroids abnormalities on the cardiovascular system.

Idiopathic hirsutism (IH) is a condition possibly related to PCOS, and is defined as hirsutism or acne with regular menses and normal circulating androgen hormone levels. IH has been previously linked with cardiovascular risk factors (6). This condition may not represent a distinct entity and may only be a milder variant of PCOS. According to the recently revised consensus criteria for PCOS diagnosis $(7,8)$, previous $\mathrm{IH}$ diagnosis would probably be characterized as belonging to the PCOS spectrum, especially as the absence of the morphology findings was not so far required for $\mathrm{IH}$ diagnosis.

Endothelial dysfunction has been suggested to play a fundamental role in the pathogenesis of atherosclerosis and thus of cardiovascular disease (CVD) (9). Venous occlusion plethysmography, a simple non-invasive method for testing endothelial function, provides the ability to detect subtle vascular abnormalities in asymptomatic patients with classic cardiovascular risk factors $(10,11)$. This method has been widely used to study the effect of several cardiovascular risk factors on endothelial function such as hypercholesterolemia (12), diabetes mellitus (13), cigarette smoking (14) and 
aging (15). Furthermore, forearm endothelial dysfunction appears to have a prognostic significance for future cardiovascular events in hypertensive patients (16). Interestingly, lower post-ischemic forearm reactive hyperemia is associated with all-cause mortality in end-stage renal disease patients independently of the presence of end-organ damage such as left ventricular hypertrophy or arteriosclerosis (17).

In this study, young women with PCOS were evaluated for possible endothelial dysfunction in comparison with healthy age-matched women and a group of young women with IH. Relationships of endothelial function with metabolic and hormonal indices were also examined.

\section{Subjects and methods}

Subjects recruited were grouped as follows: Group A: 27 women with PCOS (mean age 25.6 years), group B: 16 women with $\mathrm{IH}$ (mean age 27.8 years) and group C: 13 healthy women (mean age 25.7 years) who served as controls. The sex-hormone-binding globulin (SHBG) and free androgen index had been calculated in the groups with hirsutism during the routine assessment prior to the study. The free androgen index was 5.33 \pm 0.58 in PCOS and $3.6 \pm 0.84$ in $\mathrm{IH}$ women.

PCOS was defined as (i) menstrual irregularity due to oligomenorrhea (fewer than nine menstrual periods per year) or amenorrhea (no menstrual periods for at least three months), (ii) clinical (hirsutism, acne or male pattern balding) and/or biochemical evidence of hyperandrogenism. Although they were not included as a criterion for diagnosis, ovarian morphological changes detected by ultrasound (eight or more subcapsular follicular cysts $\leq 10 \mathrm{~mm}(18)$ and in some cases increased ovarian stroma) were present in all patients in this group.

Idiopathic hirsutism (IH) was defined as (i) presence of terminal hairs in a male-like pattern quantified by Ferriman-Gallawey score of $\geq 8$ (19), (ii) no biochemical evidence of hyperandrogenism, (iii) no menstrual cycle abnormalities and (iv) normal ovarian ultrasonographic appearance. Controls had normal ovulatory cycles and no clinical or laboratory findings of androgen excess and normal ovarian morphology on ultrasound. None of the participants received oral contraceptives, antihypertensive drugs or any other medication for the 6 months preceding the study. None of the participants was a former or current smoker. Non-ovarian causes of hyperandrogenism were excluded. All measurements were performed during the follicular phase of the menstrual cycle in those with menstrual cyclicity and at any time in the PCOS women. Recent ovulation of the amenorrheic women was excluded by measurements of progesterone levels $(<$ $5 \mathrm{nmol} / \mathrm{l})$.

Exclusion criteria were (i) arterial hypertension, (ii) diabetes mellitus, (iii) hyperlipidemia, and (iv) coronary artery disease. All participants gave informed consent and the scientific committee of our institution approved the study protocol.

\section{Study protocol}

Measurements began approximately at 20:30 h. Subjects were fasted for $12 \mathrm{~h}$. An ovarian ultrasonogram was performed in every participant during the previous day. A fasting serum sample was obtained for determination of total cholesterol, high-density lipoprotein cholesterol, triglycerides, creatinine, glucose, insulin, thyroid, steroid and pituitary hormones. Basal insulin resistance index (HOMA) was calculated according to the formula (20): Insulin resistance $=\mathrm{FI} \times \mathrm{G} / 22.5$, where $\mathrm{FI}=$ fasting insulin $(\mu \mathrm{U} / \mathrm{ml})$ and $\mathrm{G}=$ fasting glucose $(\mathrm{mmol} / \mathrm{l})$.

The body mass index (BMI) was calculated by the formula: $\mathrm{BMI}=$ weight $(\mathrm{kg}) /[\text { height }(\mathrm{m})]^{2}$.

The waist to hip ratio was measured as the ratio between the circumferences of the waist at the level midway between the lowest rib margin and the iliac crest and the hip at the widest trochanters.

Serum total testosterone and estradiol were measured using a chemiluminescence assay (ACS-180, Bayer). Serum insulin immunoreactivity was measured by ELISA (Boehringer Biochemicals, Mannheim Germany). Dehydroepiandrosterone-sulfate (DHEA-S) was measured by RIA (Radim Spa Italia, Rome, Italy). Standard methods were used for glucose, cholesterol and triglyceride determinations.

\section{Venous occlusion strain-gauge plethysmography}

Subjects were kept in a supine position in a quiet, dark, airconditioned room (constant temperature, $22{ }^{\circ} \mathrm{C}$ to $25^{\circ} \mathrm{C}$ ) throughout the study. After $10 \mathrm{~min}$ in a supine position, endothelial function of resistance arteries was assessed by measuring forearm blood flow response (FBF) during reactive hyperemia $(\mathrm{RH})$ as previously described (21). FBF was measured using a mercury-filled silastic strain-gauge plethysmograph (EC-5R, D.E Hokanson Inc.).

A wrist cuff was inflated to a pressure of $50 \mathrm{mmHg}$ above the systolic blood pressure of each subject $4 \mathrm{~min}$ before each measurement (occluded FBF), as this is the proposed duration of arterial occlusion to produce close to maximal vasodilatation of the blood vessels and maximal peak RH FBF. Furthermore, an upper arm cuff was inflated to $50 \mathrm{mmHg}$ for $7 \mathrm{~s}$ during each $15 \mathrm{~s}$ cycle using a rapid cuff inflator (EC-20, D.E Hokanson, Inc.) to occlude venous outflow from the arm. FBF output signal was transmitted to a recorder (U-228 advance Co, Nagoya, Japan). FBF was expressed as millilitres per minute per $100 \mathrm{ml}$ of forearm tissue.

Four plethysmographic measurements were averaged to yield values for FBF at baseline. After releasing the wrist-occluded cuff, FBF was measured every $15 \mathrm{~s}$ for $3 \mathrm{~min}$. The forearm vascular response to RH was then 
evaluated. Blood pressure was measured in the left arm at baseline and during RH every 1 min starting from time point 0 after release of the arterial occlusion.

\section{Derived parameters}

Percentage change of flow (dfl \%) during hyperemia was calculated as $\{[$ (reactive hyperemia FBF)-(basal flow) $] /($ basal flow $)\} \times 100$. Maximal percentage change of flow (max dfl \%) corresponds to dfl \% during peak $\mathrm{RH}$ FBF observed immediately after arterial occlusion release.

Duration of reactive hyperemia (durRH) was calculated separately for each individual by calculating the time needed for hyperemic flow to return to baseline levels as previously described (21). Baseline level for each subject was defined as the subject's basal flow \pm S.D. plus the difference of the group's lower hyperemic blood flow minus the group's basal flow.

\section{Statistical analysis}

All variables of the continuous plethysmographic parameters were expressed as mean \pm standard deviation. The normality of distribution of our data was checked using the Shapiro Wilk W test. No variable was found to have a normal distribution according to the above test. The non-parametric Mann-Whitney U test was used for comparison of continuous data with non-normal distribution. The non-parametric Spearman correlation coefficient was calculated and evaluated to identify significant associations between flow parameters and demographic traits and the lipid profiles of patients that were not normally distributed. Median regression (least absolute value) analysis was also used in order to investigate potential linear relationship between the dependent variable (durRH) and other candidate independent variables. The results were considered statistically significant if the two-tailed $P$-value was less than 0.05 .

Data were analyzed using STATA (Version 8.0, Stata Corporation, College Station, TX 77845, USA).

\section{Results}

The characteristics of the study groups are shown in Table 1 .

The durRH was shorter in PCOS group when compared with normal controls $(63.75 \pm 13.33 \mathrm{~s}$ vs $113.18 \pm 20.92 \mathrm{~s}, P=0.036)$. A similar finding was observed when PCOS were compared with IH group $(63.75 \pm 13.33 \mathrm{~s}$ vs $105 \pm 17.20 \mathrm{~s}, \quad P=0.05)$. The durRH did not differ between IH and controls (105 \pm $17.20 \mathrm{~s}$ vs $113.18 \pm 20.92 \mathrm{~s}$, ns) (Fig. 1).

A statistically significant positive linear correlation was found between the durRH and DHEA-S levels ( $r=+0.48, P=0.04)$ in the PCOS group.

When the group of PCOS was divided according to $\mathrm{BMI}$ levels in $\mathrm{BMI} \leq 25$ and $\mathrm{BMI}>25$ subgroups, this association was only marginally significant $(P=0.07$ and $P=0.08$ respectively). No significant association of DHEA-S with durRH was found when the whole population was examined as one group.

The HOMA index of basal insulin resistance, was significantly different between PCOS and control group $(2.45 \pm 0.77$ vs $0.36 \pm 0.14, P<0.0001)$ as well between the PCOS and IH groups $(2.45 \pm 0.77$ vs $0.50 \pm 0.17, P=0.002)$. The HOMA index did not differ significantly between $\mathrm{IH}$ and the control group $(0.50 \pm$ 0.17 vs $0.36 \pm 0.14, P=0.09)$. There was no significant correlation between durRH and HOMA index or testosterone levels in the PCOS group (Table 2). The FBF at rest and the peak RH FBF did not differ significantly between controls and PCOS or IH groups (Table 3). Maximum \% increase of FBF (max dfl \%) did

Table 1 Baseline characteristics of the study population.

\begin{tabular}{lccc}
\hline & PCOS $(n=27)$ & IH $(n=16)$ & Controls $(n=13)$ \\
\hline Age (year) & $25.6 \pm 5.8$ & $27.8 \pm 6.5$ & $25.7 \pm 5.6$ \\
BMl $\left(\mathrm{kg} / \mathrm{m}^{2}\right)$ & $28.4 \pm 6.6^{\mathrm{a}}$ & $25 \pm 3.3$ & $23.2 \pm 2.7$ \\
Waist/hip ratio & $0.8 \pm 0.09$ & $0.76 \pm 0.05$ & $0.76 \pm 0.04$ \\
SBP $(\mathrm{mmHg})$ & $115 \pm 20$ & $113 \pm 19$ & $109 \pm 12$ \\
DBP $(\mathrm{mmHg})$ & $75 \pm 13$ & $75 \pm 16$ & $72 \pm 9$ \\
Cholesterol (mg/dl) & $183.9 \pm 26.7$ & $176.4 \pm 28.1$ & $173.6 \pm 38.8$ \\
HDL $(\mathrm{mg} / \mathrm{dl})$ & $54 \pm 13.5$ & $59.6 \pm 16.4$ & $51 \pm 6.5$ \\
LDL $(\mathrm{mg} / \mathrm{dl})$ & $105 \pm 8.6$ & $103 \pm 10.1$ & $101 \pm 9.8$ \\
Triglycerides $(\mathrm{mg} / \mathrm{dl})$ & $108 \pm 78.6^{\mathrm{a}, \mathrm{b}}$ & $56 \pm 28.06$ & $52 \pm 19.9$ \\
Insulin $(\mu \mathrm{U} / \mathrm{ml})$ & $11.4 \pm 18.2^{\mathrm{a}}$ & $2.1 \pm 2.5^{\mathrm{c}}$ & $1.65 \pm 2.2$ \\
17ß-estradiol $(\mathrm{nmol} / \mathrm{l})$ & $0.18 \pm 0.09$ & $0.28 \pm 0.2$ & $0.33 \pm 0.2$ \\
Glucose $(\mathrm{mg} / \mathrm{dl})$ & $89.3 \pm 11$ & $86 \pm 5.4$ \\
Testosterone $(\mathrm{nmol} / \mathrm{l})$ & $2.24 \pm 0.9^{\mathrm{a}}$ & $1.92 \pm 8.5$ & $1.3 \pm 0.4$ \\
DHEA-S $(\mu \mathrm{mol} / \mathrm{l})$ & $8.97 \pm 5.5$ & $9.06 \pm 5.3$ & $0.5 \pm 0.27 \pm 3.5$ \\
HOMA index & $2.45 \pm 3.9^{\mathrm{a}, \mathrm{b}}$ & $0.5 \pm 0.6$ & $0.36 \pm 0.5$ \\
\hline
\end{tabular}

DHEA-S: dehydroepiandrosterone-sulfate; BMI: body mass index; SBP: systolic blood pressure; DBP: diastolic blood pressure; HDL: high density lipoprotein; LDL: low density lipoprotein. Values are mean \pm S.D.

${ }^{\mathrm{a}} \mathrm{P}<0.05$, PCOS vs controls, ${ }^{\mathrm{b}} P<0.05$, PCOS vs $\mathrm{IH},{ }^{\mathrm{c}} P<0.05$, IH vs controls. 


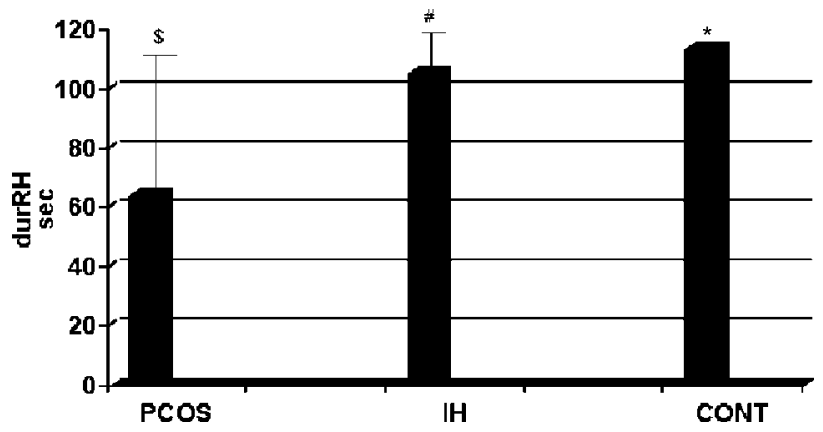

Figure 1 The duration of reactive hyperemia in $\mathrm{PCOS}, \mathrm{IH}$, and control groups. ${ }^{\star} P=0.036$ vs control; ${ }^{\$} P=0.05$ vs IH; ${ }^{\#}$ ns vs control.

not differ significantly between the three groups of our study (Table 3).

In order to exclude a potential effect of the group on the durRH, the variables which were found to differ significantly between controls, PCOS and IH groups (Table 1) were selected for median regression (least absolute value) modeling, including those variables for which the $t$ test had a $P$-value less than 0.05 . Thus we concluded that the group that the patients belonged to and insulin levels predicted linearly and significantly the durRH (Table 4) whereas we found no such associations for the other candidate variables.

\section{Discussion}

Metabolic and hormonal alterations have long been recognized as possible contributing factors to the pathophysiology of CVD and have thus been studied extensively. Relevant to this issue, in this clinical observational study, we have found impaired endothelial function expressed as impaired durRH in young women with PCOS. We have also shown that durRH is associated positively with DHEA-S levels, which is the most abundant androgen produced by the adrenals (22). To the best of our knowledge, this is the first time that a beneficial role of the androgen DHEA-S in endothelial function is reported in women with PCOS.

Endothelial dysfunction has previously been reported in PCOS either by estimation of flow-mediated dilatation (FMD) in the brachial artery of lean, obese and normal weight PCOS women $(23,24)$, or by studying leg bloodflow with an invasive technique in a small number of obese women with PCOS (25).

$\mathrm{RH}$, an adaptive mechanism of vascular endothelium to hypoxia stimulus, is affected by nitric oxide (NO) production from intact endothelial cells $(10,26,27)$. It is believed that the early phase of RH (peak RH FBF, and maxdfl \%) is related to vessel wall structure abnormalities and not to endothelial function (28). Tagawa et al. (26) have reported that NO mainly contributes to the mid and late phase of FBF response after peak vasodilatation and thus augments the durRH whereas it plays a minor role in the peak FBF that represents the early phase of RH. In our study no differences were observed in the early phase of $\mathrm{RH}$ between the study groups. On the contrary we found that durRH is significantly shorter in the study group of young PCOS women when compared both with healthy, agematched females and a group of subjects with $\mathrm{IH}$. A reduction of durRH has already been reported in hypercholesterolemic patients, while administration of an antioxidant ameliorates the durRH (21), suggesting that increased oxidative stress has causal relationship with impaired durRH in these patients. Increased oxidative stress has been observed in women with PCOS (29), so this might be the pathophysiological mechanism underlying these differences.

Table 2 Simple correlations of various metabolic and hormonal parameters with duration of reactive hyperemia (durRH) in the study groups.

\begin{tabular}{|c|c|c|c|c|c|c|}
\hline \multirow[b]{2}{*}{$\begin{array}{l}\text { Correlation of } \\
\text { durRH with: }\end{array}$} & \multicolumn{2}{|c|}{ PCO } & \multicolumn{2}{|c|}{ IH } & \multicolumn{2}{|c|}{ Controls } \\
\hline & $r$ value & $P$ value & $r$ value & $P$ value & $r$ value & $P$ value \\
\hline Age & -0.08 & 0.69 & 0.32 & 0.27 & -0.08 & 0.79 \\
\hline Weight & -0.10 & 0.62 & -0.30 & 0.30 & 0.15 & 0.64 \\
\hline Testosterone & 0.06 & 0.76 & -0.52 & 0.09 & 0.46 & 0.17 \\
\hline Waist/hip ratio & -0.043 & 0.84 & 0.05 & 0.86 & -0.09 & 0.78 \\
\hline Glucose & -0.15 & 0.46 & -0.06 & 0.82 & -0.01 & 0.98 \\
\hline BMI & -0.004 & 0.98 & -0.11 & 0.71 & -0.37 & 0.25 \\
\hline Prolactin & 0.15 & 0.51 & 0.15 & 0.64 & 0.33 & 0.31 \\
\hline Insulin & 0.19 & 0.35 & -0.50 & 0.07 & 0.29 & 0.37 \\
\hline HOMA index & 0.16 & 0.45 & 0.50 & 0.07 & 0.33 & 0.31 \\
\hline $17 \beta$-estradiol & 0.46 & 0.06 & -0.13 & 0.70 & 0.36 & 0.30 \\
\hline Progesterone & 0.06 & 0.77 & 0.22 & 0.50 & 0.01 & 1.00 \\
\hline DHEA-S & 0.48 & 0.04 & 0.40 & 0.19 & 0.01 & 0.96 \\
\hline Cholesterol & -0.17 & 0.49 & 0.66 & 0.20 & 0.14 & 0.68 \\
\hline Triglycerides & 0.17 & 0.54 & -0.24 & 0.46 & 0.15 & 0.67 \\
\hline HDL-cholesterol & 0.26 & 0.33 & 0.40 & 0.21 & 0.35 & 0.31 \\
\hline LDL-cholesterol & -0.33 & 0.40 & -0.32 & 0.30 & -0.30 & 0.35 \\
\hline
\end{tabular}


Table 3 Plethysmographic parameters in the three study groups.

\begin{tabular}{lcccc}
\hline & $\begin{array}{c}\text { PCOS } \\
(n=27)\end{array}$ & $\begin{array}{c}\text { IH } \\
(n=16)\end{array}$ & $\begin{array}{c}\text { Controls } \\
(n=13)\end{array}$ & \\
\hline $\begin{array}{l}\text { FBF at rest } \\
(\mathrm{ml} / \mathrm{min} / 100 \mathrm{ml})\end{array}$ & $4.96 \pm 2.8$ & $4.12 \pm 2.1$ & $5.4 \pm 3.2$ & $\mathrm{~ns}$ \\
$\begin{array}{l}\mathrm{Peak} \mathrm{RH} \mathrm{FBF} \\
(\mathrm{ml} / \mathrm{min} / 100 \mathrm{ml})\end{array}$ & $9.8 \pm 6.1$ & $7.49 \pm 4.9$ & $9.9 \pm 5.3$ & $\mathrm{~ns}$ \\
Max $(\mathrm{dfl} \%)$ & $102.6 \pm 81.9$ & $101.4 \pm 98.1$ & $96.4 \pm 49.9$ & $\mathrm{~ns}$ \\
\hline
\end{tabular}

The most interesting finding of our study is that in the group of PCOS, the durRH is positively correlated with DHEA-S levels, possibly showing a protective effect of DHEA-S on vascular function. Previous studies have reported that DHEA-S directly induces endothelial NO synthesis through genomic and non-genomic mechanisms characterizing human endothelial cells as primary targets for DHEA-S (30). Furthermore, DHEA-S supplementation improves endothelial function and insulin sensitivity in men (31).

Accordingly, DHEA-S levels have been reported to correlate inversely with the intima-media thickness of carotid arteries in young PCOS women $(32,33)$. Another possible explanation for the vascular protective effect of DHEA-S may be by means of prevention of platelet aggregation (34), reduction of cholesterol uptake $(35,36)$ and decrease of vascular smooth muscle cells proliferation (37). A favorable effect through conversion of DHEA-S to estradiol (38) may also contribute to the improvement of endothelial function. Interestingly, a negative relationship between DHEA-S, coronary artery disease (CAD) and atherosclerosis has been documented in cross sectional studies in young women $(39,40,41)$.

However, it is important to note that other investigators have not found associations of DHEA-S levels with cardiovascular function parameters $(42,43,44)$.

Additionally, a number of studies were designed to examine the possible association of endothelial function with DHEA-S, with negative results $(24,25,33,45)$. The discrepancy between our results and those of the previously mentioned studies could be explained by the DHEA-S much lower levels that could have obscured any effect of the hormone on endothelial function. Accordingly, no correlations were found between
DHEA-S levels and durRH in the groups having lower levels of DHEA-S in our study (Table 2). Additionally, when the whole population of our study was analyzed as one group (results not shown) the association between DHEA-S and the endothelial function index could no longer be depicted, obviously because the effect is diluted and can thus only be revealed in the case of elevated DHEA-S and/or abnormal endothelial function.

Although we have no data on free androgen index, total testosterone levels did not correlate significantly with durRH in the PCOS group in this study. Indeed the various published studies, which have examined the possible role of testosterone on vascular endothelium function and cardiovascular disease in the female population, have reported conflicting results $(46,47)$. Studies performed in young obese PCOS women have shown correlations of testosterone and insulin levels with endothelial dysfunction and increased arterial stiffness $(25,48)$. However, Mather et al. have recently reported normal endothelial function despite insulin resistance in healthy obese PCOS women (49) and additionally a lack of negative effect of androgen levels in endothelial function. It is important to note that in the study by Mather et al. levels of DHEA-S were not estimated and thus any evaluation of the potential role of DHEA-S in endothelial function was not possible.

Although the PCOS group in our study had increased HOMA insulin resistance index compared to IH group and controls, the index itself did not correlate with parameters of endothelial dysfunction. Insulin resistance has been proposed as the key factor linking hypertension, impaired glucose tolerance, obesity and lipid abnormalities with CAD in young women with PCOS (50). Indeed, several lines of evidence support the presence of a strong association between insulin resistance and endothelial dysfunction (51-54). However, a recent study designed to examine the relationship between metabolic and hormonal indices and markers of early cardiovascular disease in PCOS, showed no relationship between endothelial dysfunction and insulin resistance. Insulin resistance in this study seems to exert its effect on the peripheral vascular system through the arterial media layer and not the endothelium, as evidenced by its association with arterial stiffness and pulse wave velocity (33).

Table 4 Median regression for durRH.

\begin{tabular}{|c|c|c|c|c|c|c|c|}
\hline \multirow{2}{*}{$\begin{array}{l}\text { Variable } \\
\text { Group (categories) } \\
\text { vs controls (reference) }\end{array}$} & \multirow{2}{*}{$\begin{array}{l}\text { PCOS group } \\
\text { IH Group }\end{array}$} & \multirow{2}{*}{$\begin{array}{r}\text { Coef. } \\
-113.781\end{array}$} & \multirow{2}{*}{$\begin{array}{c}\begin{array}{c}\text { Standard } \\
\text { error }\end{array} \\
45.63711\end{array}$} & \multirow{2}{*}{$\frac{t}{-2.49}$} & \multirow{2}{*}{$\begin{array}{l}\boldsymbol{P}>\boldsymbol{t} \\
0.016\end{array}$} & \multicolumn{2}{|c|}{ (95\% Confidence interval) } \\
\hline & & & & & & -205.756 & -21.8049 \\
\hline $\begin{array}{l}\text { Insulin } \\
\text { Intercept }\end{array}$ & IH Group & $\begin{array}{l}-30 \\
1.567944 \\
133.7456\end{array}$ & $\begin{array}{l}49.33685 \\
0.636955 \\
36.19222\end{array}$ & $\begin{array}{c}-0.61 \\
2.46 \\
3.7\end{array}$ & $\begin{array}{l}0.546 \\
0.018 \\
0.001\end{array}$ & $\begin{array}{c}-129.432 \\
0.284247 \\
60.80502\end{array}$ & $\begin{array}{l}69.43188 \\
2.851642 \\
206.6863\end{array}$ \\
\hline
\end{tabular}

(Number of obs $=48$, Min sum of deviations $=2477.352$, Pseudo $R^{2}=0.1659$ ). 
IH may represent a condition possibly related to PCOS; however, we did not find any differences in durRH between this group and controls. This suggests that if $\mathrm{IH}$ is indeed related to PCOS, it probably represents a very mild variant and supports the view of a large heterogeneity in the PCOS syndrome.

The findings of our study may offer some explanation for the observed discrepancy between the calculated risk level for cardiovascular events and the fact that the number of deaths due to CVD was not increased in the two published studies of mortality in women with PCOS $(55,56)$. This observation leads to the speculation that PCOS women are probably of "intermediate phenotype" regarding cardiovascular risk. It is possible that increased DHEA-S levels, frequently encountered in PCOS, and their putative protective effect on the endothelium may partly explain this complex association. It is thus possible that anti-androgen treatment might not be very suitable at least for the preservation of vascular health in PCOS, while the favorable effect of insulin sensitizers in the vasculature may only be mediated through their effect on insulin resistance and not through the resulting amelioration in androgen levels. It seems that the lifestyle modifications need to be the focus of advice in these women to improve endothelial dysfunction and possibly reduce cardiovascular risk.

The limitations of our study include the small number of subjects in each group and its observational character. However, we studied a population covering considerable part of the spectrum of conditions associated with hirsutism and putative hyperandrogenism. Diagnostic criteria utilized in clinical trials of such conditions may pose a further limitation since they are not absolutely sufficient for clinical diagnosis and grouping of the population studied (8). Our findings are not confounded by obesity, which has several relevant influences on its own. Endothelial-independent vasodilatation was not estimated in our study, so we cannot exclude an effect of DHEA-S on smooth muscle cell function of resistance arteries in PCOS women. One further limitation is the lack of data on SHBG and consequently on free androgen index (FAI) during the vascular studies which may obscure the potential impact of testosterone in endothelial function but we support the idea that this limitation does not alter the main message of our study: i.e. the possible protective role of DHEA-S in endothelial function in women with PCOS.

In conclusion, endothelial dysfunction may be the early sign for complications of cardiovascular system in young PCOS women. These preliminary findings indicate that increased DHEA-S levels may offer a cardioprotective advantage that attenuates the effects of the cardiovascular risk factors that accompany the PCOS. It should be pointed out that these findings do not support the therapeutic use of DHEA-S and that larger cohort studies with longitudinal follow up are needed to determine the possible role of androgens in women with PCOS.

\section{References}

1 Ovalle F \& Azziz R. Insulin resistance, polycystic ovary syndrome and type 2 diabetes mellitus. Fertility Sterility $2002 \quad \mathbf{7 7}$ 1095-1105.

2 Wild R, Painter P, Coulson P, Carruth K \& Ranney G. Lipoprotein lipid concentrations and cardiovascular risk in women with polycystic ovary syndrome. Journal of Clinical Endocrinology and Metabolism $1985 \mathbf{6 1}$ 946-951.

3 Holte J, Gennarelli G, Berne C, Bergh T \& Lithell H. Elevated ambulatory day time blood pressure in women with polycystic ovary syndrome: a sign of pre-hypertensive state? Human Reproduction 199611 23-28.

4 Orio F, Palomba S, Spinelli L, Cascella T, Tauchmanova L, Zullo F, Lombardi G \& Colao A. The cardiovascular risk of young women with polycystic ovary syndrome: an observational analytical, prospective case-control study. Journal of Clinical Endocrinology and Metabolism 200489 3696-3701.

5 Wu FC \& von Eckardstein A. Androgens and coronary artery disease. Endocrine Reviews 200324 183-217.

6 Erdem NT, Ercan M, Akyolcu MC \& Gundogdu S. Plasma viscosity is an early cardiovascular risk factor in hirsute women with eumenorrhea or oligomenorrhea. Fertility Sterility 2003 80(5) 1195-1198.

7 The Rotterdam ESHRE/ASRM-sponsored PCOS consensus workshop group. Revised 2003 consensus on diagnostic criteria and long term health risks related to polycystic ovary syndrome. Fertility Sterility 2004 81(1) 19-25.

8 The Rotterdam ESHRE/ASRM-Sponsored PCOS consensus workshop group. Revised 2003 consensus on diagnostic criteria and long-term health risks related to polycystic ovary syndrome (PCOS). Human Reproduction 2004 19(1) 41-47.

9 Cannon RO, III. Role of nitric oxide in cardiovascular disease: Focus on the endothelium. Clinical Chemistry $1998 \mathbf{4 4}$ 1809-1819.

10 Dakak N, Husain S, Mulcahy D, Andrews NP, Panza JA, Waclawiw M, Schenke W \& Quyyumi AA. Contribution of nitric oxide on reactive hyperaemia. Impact on endothelial dysfunction. Hypertension 199832 9-15.

11 Creager MA, Cooke JP, Mendelson ME, Gallagher SJ, Coleman SM, Loscazlo J \& Dzau VJ. Impaired vasodilation of forearm resistance vessels in hypercholesterolaemic humans. Journal of Clinical Investigation $1990 \mathbf{8 6} 228-234$.

12 Chowienczyk PJ, Watts GF, Cockcroft JR \& Ritter JM. Impaired endothelium-dependent vasodilation of forearm resistance vessels in hypercholesterolaemia. Lancet 1992340 1430-1432.

13 Makimattila S, Liu ML, Vakkilainen J, Schlenzka A, Lahdenpera S, Syvanne M, Mantysaari M, Summanen P, Bergholm R, Taskinen M \& Yki-Jarvinen H. Impaired endothelium-dependent vasodilation in type 2 diabetes. Relation to LDL size, oxidized LDL, and antioxidants. Diabetes Care 199922 973-981.

14 Heitzer T, Yla-Herttuala S, Luoma J, Kurz S, Munzel T, Just H, Olschewski M \& Drexler H. Cigarette smoking potentiates endothelial dysfunction of forearm resistance vessels in patients with hypercholesterolemia: role of oxidized LDL. Circulation 1996 93 1346-1353.

15 Taddei S, Virdis A, Mattei P, Natali A, Ferrannini E \& Salvetti A. Aging and endothelial function in normotensive subjects and patients with essential hypertension. Circulation $1995 \mathbf{9 1}$ 1981-1987.

16 Perticone F, Ferraro A, Chello M, Mastroroberto P, Verdecchia P \& Schillaci G. Prognostic significance of endothelial dysfunction in hypertensive patients. Circulation 2001 104(2) 191-196. 
17 London G, Pannier B, Agharazii M, Guerin A, Verbeke F \& Marchais S. Forearm reactive hyperemia and mortality in end stage renal disease. Kidney International 2004 65(2) 700-704.

18 Zawadzki SK \& Dunaif A. Diagnostic criteria for polycystic ovary syndrome: Towards a rational approach. In Polycystic Ovary Syndrome, Current Issues in Endocrinology and Metabolism, pp 377-384. Eds A Dunaif, JR Givens, FP Haseltine \& GR Merriam. vol. 4, ch.32, Boston: Blackwell, 1992

19 Ferriman D \& Gallwey JD. Clinical assessment of body hair growth in women. Journal of Clinical Endocrinology and Metabolism 1961 21 1440-1447.

20 Mathews DR, Hosker JP, Rudenski AS, Naylor BA, Treacher DF \& Turner RC. Homeostasis Model Assessment: insulin resistance and beta-cell function from fasting plasma glucose and insulin concentrations in man. Diabetologia 198528 412-419.

21 Protogerou A, Lekakis J, Kontoyanni D, Stamatelopoulos K, Tsotsoros N, Papaioannou T, Tryfonopoulos D, Papamichael C \& Stamatelopoulos S. Effect of ascorbic acid on forearm reactive hyperemia in patients with hypercholesterolemia. European Journal of Cardiovascular Prevention and Rehabilitation 200411 (2) $149-154$.

22 Lamberts S, van den Beld A \& van der Lely A. The endocrinology of age. Science $1997 \mathbf{2 7 8} 419-424$.

23 Kravariti M, Naka K, Kalantaridou S, Kazakos N, Katsouras C, Makrigiannakis A, Paraskevaidis E, Chrousos G, Tsatsoulis A \& Michalis L. Predictors of endothelial dysfunction in young women with polycystic ovary syndrome. Journal of Clinical Endocrinology and Metabolism 200590 5088-5095.

24 Orio F, Palomba S, Cascella T, De Simone B, Di Biase S, Russo T, Labella D, Zullo F, Lombardi G \& Colao A. Early impairment of endothelial structure and function in young normal weight women with polycystic ovary syndrome. Journal of Clinical Endocrinology and Metabolism 200489 4588-4593.

25 Paradisi G, Steinberg H, Hempfling A, Cronin J, Hook G, Shepard M \& Baron A. Polycystic ovary syndrome is associated with endothelial dysfunction. Circulation 2001103 1410-1415.

26 Tagawa T, Imaizumi T, Endo T, Shiramoto M, Harasawa Y \& Takeshira A. Role of nitric oxide in reactive hyperaemia in human forearm vessels. Circulation 199490 2285-2290.

27 Engelke KA, Halliwill DN, Proctor NM, Dietz NM \& Joyner MJ. Contribution of nitric oxide and prostaglandins to reactive hyperaemia in the human forearm. Journal of Applied Physiology 199681 1807-1814.

28 Cortella A, Zambon S, Sartore S, Piarulli F, Calabro A, Manzato E \& Crepaldi G. Calf and forearm blood flow in hypercholesterolemic patients. Angiology 200051 309-318.

29 Sabunku T, Vural H, Harma M \& Harma M. Oxidative stress in polycystic ovary syndrome and its contribution to the risk of cardiovascular disease. Clinical Biochemistry 200134 407-413.

30 Simoncini T, Mannella P, Fornari L, Varone G, Caruso A \& Genazzani A. Dehydroepiandrosterone modulates endothelial nitric oxide synthesis via direct genomic and nongenomic mechanisms. Endocrinology 2003144 3449-3455.

31 Kawano H, Yasue H, Kitagawa A, Hirai N, Yoshida T, Soejima H, Miyamoto S, Masahiro N \& Ogawa H. Dehydroepiandrosterone supplementation improves endothelial function and insulin sensitivity in men. Journal of Clinical Endocrinology and Metabolism 200388 3190-3195.

32 Vryonidou A, Papatheodorou A, Tavridou A, Terzi T, Loi V, Vatalas I-A, Batakis N, Phenekos C \& Dionyssiou-Asteriou A. Association of hyperandrogenemic and metabolic phenotype with carotid intima-media thickness in young women with polycystic ovary syndrome. Journal of Clinical Endocrinology and Metabolism 2005 $902740-2746$.

33 Meyer C, McGrath B, Cameron J, Kotsopoulos D \& Teede H. Vascular dysfunction and metabolic parameters in polycystic ovary syndrome. Journal of Clinical Endocrinology and Metabolism 2005 90(8) 4630-4635.
34 Jesse RL, Loesser K, Eich DM, Qian YZ, Hess ML \& Nestler JE. Dehydroepiandrosterone inhibits human platelet aggregation in vitro and in vivo. Annals of the New York Academy of Sciences $1995 \mathbf{7 7 4} 271-280$.

35 Arad Y, Badimon JJ, Badimon L, Hembree WC \& Ginsberg HN. Dehydroepiandrosterone feeding prevents aortic fatty streak formation and cholesterol accumulation in cholesterol-fed rabbit. Arteriosclerosis 19899 159-166.

36 Gordon GB, Bush DE \& Weisman HF. Reduction of atherosclerosis by administration of dehydroepiandrosterone. Journal of Clinical Investigation 198882 712-720.

37 Williams MR, Ling S, Dawood T, Hashimura K, Dai A, Li H, Liu JP, Funder W, Sudhir K \& Komesaroff PA. Dehydroepiandrosterone inhibits human vascular smooth muscle cell proliferation independent of ARs and ERs. Journal of Clinical Endocrinology and Metabolism 200287 176-181.

38 Labrie F, Belanger A, Simard J, Luu-The V \& Labrie C. DHEA and peripheral androgen and estrogen formation: intracrinology. Annals of the New York Academy of Sciences 1995 774 16-28.

39 Herrington DM, Gordon GB, Achuff SC, Trejo JF, Weisman HF, Kwiterovich PO, Jr \& Pearson TA. Plasma dehydroepiandrosterone and dehydroepiandrosterone sulfate in patients undergoing diagnostic coronary angiography. Journal of American College of Cardiology 199016 862-870.

40 Slowinska-Srzednicka J, Malczewska B, Srzednicki M, Chotkowska E, Brzezinska A, Zgliczynski W, Ossowski M, Jeske W, Zgliczynski S \& Sadowski Z. Hyperinsulinaemia and decreased plasma levels of dehydroepiandrosterone sulfate in premenopausal women with coronary heart disease. Journal of Internal Medicine 1995237 $465-472$.

41 Bernini GP, Sagro M, Moretti A, Argenio GF, Barlascini CO, Cristofani R \& Salvetti A. Endogenous androgens and carotid intimal-medial thickness in women. Journal of Clinical Endocrinology and Metabolism 199984 2008-2012.

42 Barrett-Connor E \& Goodman-Gruen D. The epidemiology of DHEAS and cardiovascular disease. Annals of the New York Academy of Sciences $1995 \mathbf{7 7 4} 259-270$.

43 Berr C, Lafon S, Debuire B, Dartigues JF \& Baulieu E-E. Relationships of dehydroepiandrosterone sulfate in the elderly with functional, psychological and mental status and short-term mortality: a French community-based study. Proceedings of the National Academy of Sciences of the United States of America 199693 13410-13415.

44 Kiechl S, Willeit J, Bonora E, Schwarz S \& Xu Q. No association between dehydroepiandrosterone sulfate and development of atherosclerosis in a prospective population study (Bruneck Study). Arteriosclerosis Thrombosis and Vascular Biology 200020 1094-1100.

45 Meyer C, McGrath BP \& Teede H. Overweight women with polycystic ovary syndrome have evidence of subclinical cardiovascular disease. Journal of Clinical Endocrinology and Metabolism $2005905711-5716$.

46 Worboys S, Kotsopoulos D, Teede H, McGrath B \& David SR. Evidence that parenteral testosterone therapy may improve endothelium-dependent and independent vasodilatation in postmenopausal women already receiving estrogen. Journal of Clinical Endocrinology and Metabolism 200188 158-161.

47 Barrett-Connor EL \& Goodman-Gruen D. Prospective study of endogenous sex hormones and fatal cardiovascular disease in postmenopausal women. British Medical Journal 1995311 1193-1196.

48 Kelly C, Speirs A, Gould G, Petrie J, Lyall H \& Connel J. Altered vascular function in young women with polycystic ovary syndrome. Journal of Clinical Endocrinology and Metabolism 2002 $87742-746$.

49 Mather K, Verma S, Corenblum B \& Anderson T. Normal endothelial function despite insulin resistance in healthy women with the polycystic ovary syndrome. Journal of Clinical Endocrinology and Metabolism 200085 1851-1856. 
50 Dunaif A. Insulin resistance and the polycystic ovary syndrome: mechanisms and implications for pathogenesis. Endocrine Reviews 199718 774-800.

51 Steinberg H, Chaker H, Leaming R, Johnson A, Brechtel G \& Baron A. Obesity/insulin resistance is associated with endothelial dysfunction. Implications for the syndrome of insulin resistance. Journal of Clinical Investigation $1996 \mathbf{9 7}$ 2601-2610.

52 Cleland S, Petrie J, Ueda S, Elliott H \& Connell J. Insulin as a vascular hormone: implications for the pathophysiology of cardiovascular disease. Clinical and Experimental Pharmacology $\mathcal{E}$ Physiology 199825 175-184.

53 Paradisi G, Steinberg H, Marguette K, Hook G \& Baron A. Troglitazone therapy improves endothelial function to near normal levels in women with polycystic ovary syndrome. Journal of Clinical Endocrinology and Metabolism $2003 \mathbf{8 8} 576-580$.
54 Vincent D, Ilany J, Kondo T, Naruse K, Fisher S, Kisanuki Y, Bursell S, Yanagisawa $M$ \& King G. The role of endothelial insulin signalling in the regulation of vascular tone and insulin resistance. Journal of Clinical Investigation 2003111 1372-1380.

55 Pierpoint T, McKeigue PM, Isaacs AJ, Wild SH \& Jacobs HS. Mortality of woman with polycystic ovary syndrome at long term follow up. Journal of Clinical Epidemiology 199851 581-586.

56 Wild SH, Pierpoint T, McKeigue PM \& Jacobs HS. Cardiovascular disease in women with polycystic ovary syndrome at long-term follow-up: a retrospective cohort study. Clinical Endocrinology 2000 52 595-600.

Received 16 November 2005

Accepted 1 March 2006 